\title{
Software Development and Construction of Log Periodic Dipole Antenna Using MATLAB
}

\author{
Vijay S. Kale ${ }^{1}$, Dnyandev B. Patil ${ }^{2}$ \\ Associate Professor, Department of Electronic Science, KTHM College, Nashik, Maharashtra, India ${ }^{1}$ \\ M. Phil. student, Department of Electronic Science, KTHM College, Nashik, Maharashtra, India ${ }^{2}$
}

\begin{abstract}
Technological advantages in solar activities particularly in solar radio burst (type I, II, III, IV, V) in radio region have created a demand of designing and constructing of Log Periodic Dipole Antenna (LPDA) to monitor. LPDA also plays an important role in modern communication systems such as TV, radar etc. The lengths and spacing of the elements of a LPDA are increases logarithmically from one end to the other. This paper presents the types of LPDA, mathematical equations required to design, flow-chart, MATLAB (MATRIX LABORATORY) code to obtain the antenna parameters and structure dimensions of the antenna elements to construct and the details of constructed LPDA of frequency range of $160 \mathrm{MHz}$ to $1900 \mathrm{MHz}$ with 24 elements. MATLAB tools and built-in math functions enables to explore multiple approaches and reach a solution faster than traditional programming languages, such as $\mathrm{C} / \mathrm{C}++$ or Java. It provides a good accuracy to calculate LPDA structure parameters required for LPDA design.
\end{abstract}

Keywords: LPDA, MATLAB, Flow-chart, Program, e-CALLISTO, Solar burst.

\section{INTRODUCTION}

The solar radio burst has made a great progress in more than a decade. The ground observations are one of the most significant for space weather issue. To collect data, antenna is used to transmit or receive electromagnetic waves. The propagation in both cases is the same due to the principle of reciprocity. The log periodic dipole array antenna (LPDA) has attracted much attention because of the broadband frequencies and more sensitivity to detect signal of the Sun and also it is economical and practical to implement.

In 1960, Isbell [1] first introduced the broad band LPDA in free space. It has an end-fire radiation pattern which is needed for more applications [2, 3], Carrel [2] proposed standard approach for the design of the traditional LPDA antennas. A traditional LPDA antenna with wire dipole elements can achieve wide bandwidth of 10:1 and high gain of $10 \mathrm{~dB}$. The log periodic term is derived because of the uniform spacing between the resonant frequencies of antennas in a log periodic scale.

The bandwidth of such an antenna depends on the precision in manufacturing the smallest element in the array and the size of the largest element in the array [4]. It is a frequency independent. Log periodic dipole array antenna consists of an array of linear dipoles known as driven elements, each of different length and spacing between them. They has geometries that is specified by angles. These antennas are primarily used in the $10 \mathrm{MHz}-$ $10 \mathrm{GHz}$ region in a variety of practical applications such as Television, point-to-point communication, feeds for reflectors and lenses, etc.[5].

There are different types of LPDA. Frequency independent split beam antenna is a logarithmically periodic antenna provides a split beam having sensitivity to well-defined null condition that makes it useful in direction finding applications. Log-periodic zig-zag antenna is a log periodic dipole type antenna. It is having a unidirectional radiation pattern and a relatively constant impedance level which is substantially independent of frequency over a wide bandwidth. Such an antenna is especially advantageous for minimizing signal losses in the commercial television frequency range. Log-periodic monopole antenna is a vertically-polarized log-periodic monopole antenna that comprises two closely spaced arrays of elements over a ground plane and connected to a balanced feed source. The arrays are separately excited out of phase by the source. Elements are in the shapes of trapezoidal, pseudo-trapezoidal and triangular. Twin zig zag log periodic antenna is identical conductive zig-zag structures, lies side-by-side in close proximity to each other in substantially the same plane of a planar dielectric board. Printed circuit LPDA includes dipole elements with arms having reduced size through use of high effective permittivity substrate portions. The radiation efficiency degradation generally associated with the use of a high permittivity substrate [6].

There are three important parameters while designing criss-cross LPDA antenna- scale factor $(\tau)$ that specifies the relative lengths and spacing factor $(\sigma)$ that specifies the relative spacing of the antenna elements and the apex angle $(\alpha)$. As we know, LPDA is frequency independent, the electrical properties such as the mean resistance level $\mathrm{R}_{0}$, characteristic impedance of the feed line $\mathrm{Z}_{0}$ and driving-point admittance $Y_{0}$ vary periodically with the logarithm of the frequency. It is the basic of the range of frequency due to number of elements. As the frequency $f_{1}$ is shifted to another frequency $f_{2}$ within the pass band of the antenna, the relationship is;

$$
\mathrm{f}_{2}=\mathrm{f}_{1} / \tau \text { where, } \tau \text { is a design parameter }(\tau<1.0) \text { [4]. }
$$

The parameter $\alpha$, is one-half the apex angle and is derived from $\tau$ and $\sigma$. Typical designs of LPDA have apex half angles of $10^{\circ} \leq \alpha \leq 45^{\circ}$ and $0.7 \leq \tau \leq 0.95$ [4]. To compute such parameter design uses different methods that consist 
of complicated mathematical formulae. All design Number of element: parameters are needed to calculate accurately to achieve accuracy of design and to improve the performance of the antenna. This paper mentions the mathematical steps, flow-chart and the MATLAB program. The MATLAB software is developed to design LPDA for for Compound Astronomical Low-cost Low-frequency Instrument for Spectroscopy and Transportable Observatory (CALLISTO). LPDA antenna is constructed for frequency range of $160 \mathrm{MHz}$ to $1900 \mathrm{MHz}$ with 24 elements.

MATLAB is developed by Math Works INC. U.S. [7].It is a high-level language and interactive environment for numerical computation, visualization, and programming. Its built-in math functions enable to explore multiple approaches and reach a solution faster than traditional programming languages, such as $\mathrm{C} / \mathrm{C}++$ or Java. It consists of GUI that helps in designing and Simulink to design time varying system, simulate design and graphical windows for plotting 2D or 3D graphs [8].

\section{FORMULAE USED IN DESIGN}

Geometric constant $\tau$ :

$$
\tau=\frac{f 2}{f 1} \text { Where, } \mathrm{f}_{2}>\mathrm{f}_{1}
$$

Spacing factor $\sigma$ :

$$
\sigma=\frac{R_{n+1}-R_{n}}{2 l_{n+1}}
$$

Half apex angle:

$$
\alpha=\tan ^{-1}\left[\frac{1-\tau}{4 \sigma}\right]
$$

Band-width of active region:

$$
\mathrm{B}_{\mathrm{ar}}=1.1+7.7(1-\tau)^{2} \cot \alpha
$$

Required band-width:

$$
\begin{aligned}
& \mathrm{B}=\frac{F \max }{F \min } \\
& \mathrm{B}_{\mathrm{s}}=\mathrm{B} \times \mathrm{B}_{\mathrm{ar}} \\
& B s=B \times B a r \\
& \quad B s=B[1.1=7.7(1-\tau) 2 \cot \alpha
\end{aligned}
$$

Where,

$B s=$ designed bandwidth

$\mathrm{B}=$ desired bandwidth

Bar= active region bandwidth.

Length of the structure:

$$
L=\frac{\lambda \max }{4}\left[1-\frac{1}{B s}\right] \cot \alpha
$$

Where,

$$
\lambda \max =\frac{v}{F \min }
$$

Virtual apex length Vapex:

$$
\text { Vapex }=\frac{\left(2 \times\left(\frac{\lambda_{\max } \times 3.2805}{2}\right) \sigma\right)}{\frac{1}{\tau}}
$$

$$
N=1+\frac{\ln (B s)}{\ln \left(\frac{1}{\tau}\right)}
$$

Characteristic impedance Za:

$$
Z a=120\left[\ln \left(\frac{\ln }{d n}\right)-2.25\right]
$$

Where,

$\frac{l n}{d n}$ is the length-to-diameter ratio of the $n$th element.

Mean radiation resistance of input impedance:

$$
\mathrm{R} 0=\frac{\mathrm{Z} 0}{\sqrt{1+\frac{\mathrm{Z} 0}{4 \sigma^{\prime} \mathrm{Za}}}}
$$

Centre to centre spacing of feeder line:

$$
S=d \times \cosh \left(\frac{Z 0}{120}\right)
$$

Where,

$\mathrm{d}$ is diameter of dipole in inch.

$\mathrm{Z}_{0}$ is characteristic impedance

Relative mean spacing, $\sigma$ '

$$
\sigma^{\prime}=\frac{\sigma}{\sqrt{\tau}}
$$

Optimized values for $\sigma$ can be obtained using fig.1 [4]

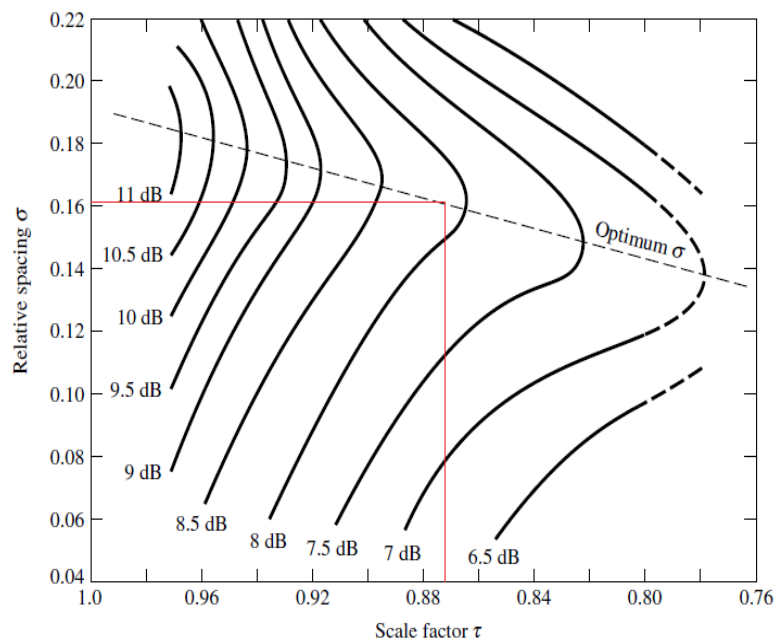

Fig.1. Computed Contours of constant directivity versus $\sigma$ and $\tau$.

Stub length:

$$
\text { Stub length }=\frac{\left[\frac{\lambda_{\max }}{8}\right]}{\tau} \times 12
$$

... in inch. (12)

The mathematical equation from 1 to 11 are used to develop flow-chart and MATLAB program. 


\section{III.FLOWCHART FOR LPDA DESIGN}

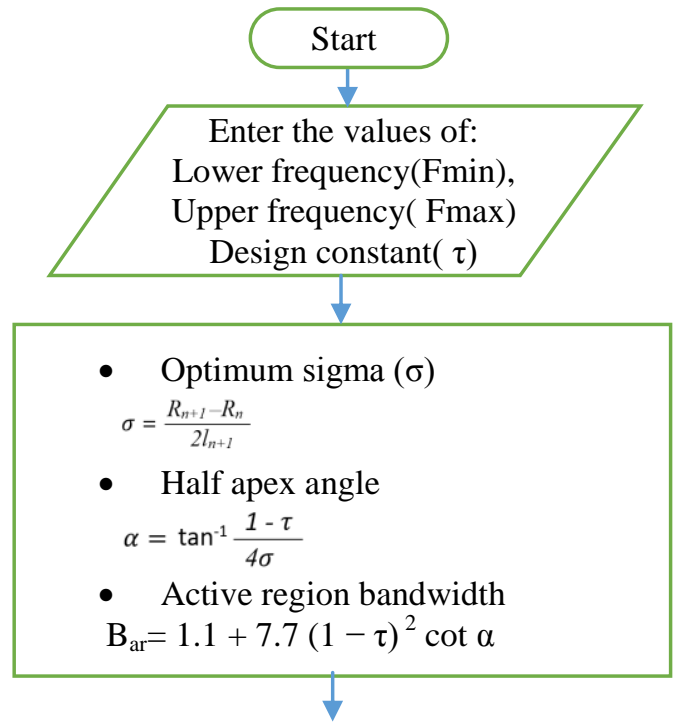

- $\quad$ Required band-width (B), Design band-width (Bs) :

$B=$ Fmax $/$ Fmin

$B_{s}=B \times B_{a r}$

- $\quad$ Maximum wavelength $\lambda_{\max }=\frac{v}{F_{\min }}$ in meter

- Length of the structure $\mathrm{L}=\frac{\lambda_{\text {max }}}{4}\left[1-\frac{1}{B s}\right] \cot \alpha$

- Virtual apex length

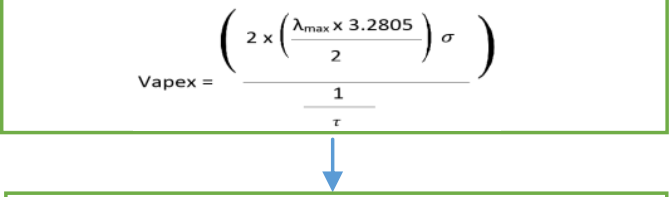

- Number of elements, $\mathrm{N}$ $\mathrm{N}=1+\frac{\ln (B s)}{\ln (1 / \tau)}$

- Relative mean spacing: $\sigma^{\prime}=\frac{\sigma}{\sqrt{\tau}}$

- Characteristic impedance Za

$$
Z a=120\left\lceil\ln \left(\frac{\ln }{d n}\right)-2.25\right\rceil
$$

- Stub length $=\left(\lambda_{\max } / 8\right) /$ tau $) \times 12 \ldots$ in inch.

- Radiation resistance level of input impedance

$$
\mathrm{R} 0=\frac{\mathrm{Z} 0}{\sqrt{1+\frac{\mathrm{Z} 0}{4 \sigma^{\prime} \mathrm{Za}}}}
$$

- Centre to centre spacing of feeder line

$$
S=d \times \cosh \left(\frac{Z 0}{120}\right)
$$

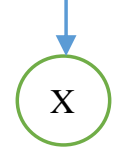

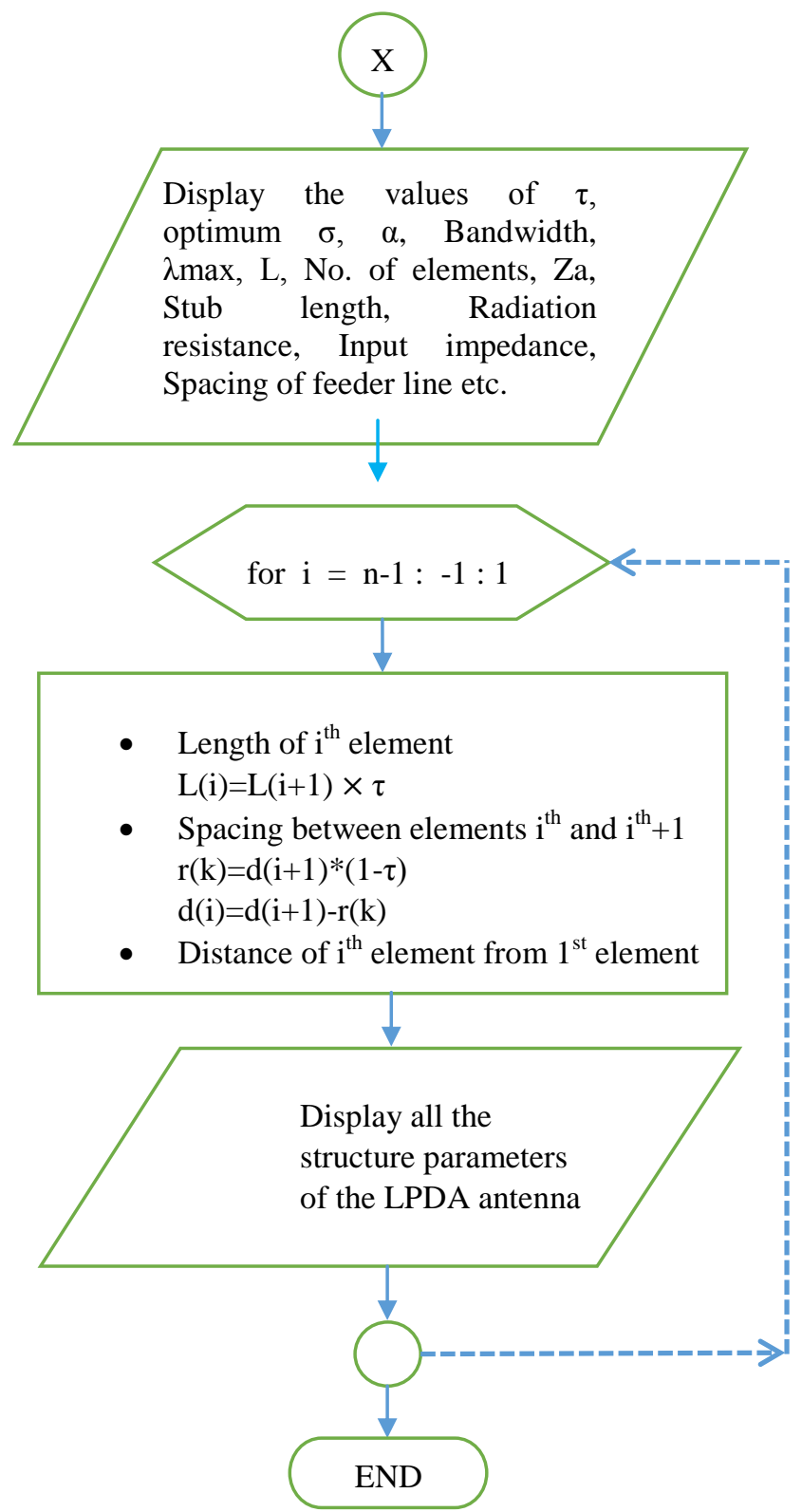

IV. MATLAB PROGRAM FOR LPDA

Equations (1-11) are implemented in MATLAB program.

\%DESIGNING OF A LOG-PERIODIC ANTENNA FOR ANY FREQUENCY RANGE

\%Designed by Dnyandev B. Patil.

clc

clearall

disp('DESIGNING OF A LOG-PERIODIC ANTENNA FOR ANY FREQUENCY RANGE ');

$\operatorname{disp}(')$;

$\mathrm{a}=$ float ( 'double' );

$1(100)=$ float $($ 'double' $) ; \operatorname{Rn}(100)=$ float $($ 'double' $)$; $\mathrm{gtl}=0.0 ; \mathrm{gt} 2=0.0 ; \mathrm{gt} 3=0.0$;

Fmin =input('Enter the value of lower frequency in $\mathrm{MHz}$, Fmin = ');

Fmax=input('Enter value of upper frequency in $\mathrm{MHz}$, Fmax $=$ '); dmax=input('Enter diameter of largest element (in inch), dmax $=$ '); 
tau=input('Enter the value of tau (0.7 to 0.95$)$, tau= ');

Fmin $=$ Fmin $* 10^{\wedge} 6 ; \mathrm{Fmax}=\mathrm{Fmax} * 10^{\wedge} 6$;

sigma $=0.243 *$ tau -0.051 ;

$\operatorname{disp}(')$;

disp(['The value of sigma (optimum sigma ) is ',

num2str(sigma)]);

alpha=atand $((1-\operatorname{tau}) /(4 * \operatorname{sigma}))$

alpha $1=2 *$ alpha;

$\operatorname{disp}([$ 'Full apex angle, alpha =',num2str(alpha1),' deg']);

Bar $=1.1+\left(7.7 *\left((1-\text { tau })^{\wedge} 2\right) * \operatorname{cotd}(\right.$ alpha $\left.)\right)$;

fprintf('Bandwidth of Active region $=\% \mathrm{f} \mathrm{MHz} \backslash n$ ',Bar);

$\mathrm{B}=$ Fmax/Fmin;

$\operatorname{disp}([$ Bandwidth, $\mathrm{B}=$ ', num2str(B),' MHz']);

$\mathrm{Bs}=(\mathrm{B} * \mathrm{Bar})$;

fprintf('Designed bandwidth $=\% \mathrm{f} \mathrm{MHz} \backslash \mathrm{n}$ ',Bs);

$\mathrm{c}=3 * 10^{\wedge} 8$

Lmax=(c/Fmin $) ; \%$ meter

$\operatorname{disp}([$ The Maximum wavelength in meter, $\operatorname{Lmax}=$,

num2str(Lmax)]);

$12=$ Lmax $* 3.2805 ; \%$ feet

fprintf('Max wavelength $=\%$ f feet $\backslash n ', 12)$;

$\mathrm{L}=(\mathrm{Lmax} / 4) *(1-(1 / \mathrm{Bs})) * \operatorname{cotd}($ alpha $)$;

$\mathrm{L} 1=\mathrm{L} * 3.2805$; $\%$ feet

fprintf('Total length of structure $=\%$ f feet $\backslash n$ ',L1);

Vapex $=(2 *(12 / 2) * \operatorname{sigma}) /(1-$ tau $)$;

$\operatorname{disp}([$ 'The Maximum vertual apex length, $\mathrm{V} \max =$

',num2str(Vapex),' feet']);

$\mathrm{N}=1+(\log (\mathrm{Bs}) / \log (1 / \mathrm{tau}))$;

$\mathrm{n}=\operatorname{round}(\mathrm{N})$;

fprintf('No. of elements are, $\mathrm{N}=\% \mathrm{f} \backslash \mathrm{n}$ ',n);

sigma1 $=$ sigma/sqrt(tau);

fprintf('Relative mean spacing $=\%$ f $\backslash n$ ',sigma 1$)$;

$\mathrm{LN}=12 / 2$; \%length of nth element in feet

$\mathrm{Lnn}=\mathrm{LN} * 12$;

stub_length $=((12 / 8) / \mathrm{tau}) * 12$;

$\operatorname{disp}([$ 'stud length =',num2str(stub_length), inch']);

$\mathrm{za}=120 *(\log ((\mathrm{LN} * 12) / \mathrm{dmax})-2.25)$;

fprintf('Average characteristic impedance, $\mathrm{za}=\% \mathrm{f}$ ohms

In',za);

Rin=50;

Zrel=za/Rin;

fprintf('Relative characteristic impedance, $\mathrm{Zrel}=\%$ f ohms In',Zrel);

$\mathrm{VAR}=1.2$

$\mathrm{z} 0=\mathrm{VAR} * \mathrm{Rin}$;

fprintf('Characteristic impedance of Feeder line, Z0 =\% $\mathrm{f}$

ohms $\backslash n ', z 0)$;

$\mathrm{R} 0=\mathrm{z} 0 /(\operatorname{sqrt}(1+(\mathrm{z} 0 /(4 * \operatorname{sigma} 1 * \mathrm{za}))))$;

disp(['Mean Radiation resistance level of input impedance

= ',num 2 str(R0),' ohm']);

$\operatorname{dir}=10 * \log (4 *(\operatorname{Lmax} / 2) / \operatorname{Lmax})$;

$\operatorname{disp}([$ 'Directivity =',num2str(dir),' dB']);

$\mathrm{fs}=(\operatorname{dmax} *(\cosh (\mathrm{z0} / 120))) * 2.54$;

$\mathrm{s}=$ Vapex $* 30.48$;

fprintf('Centre-to-centre spacing of feeder line conductor

$=\% \mathrm{f} \mathrm{cm} \backslash \mathrm{n}$ ',fs);

$\mathrm{L}(\mathrm{n})=\mathrm{LN} * 12$;

$\mathrm{d}(\mathrm{n})=\mathrm{s}$;

$\mathrm{k}=\mathrm{n}$;

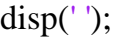

$\operatorname{disp}(')$; for $\mathrm{i}=\mathrm{n}-1:-1: 1$

$\mathrm{L}(\mathrm{i})=\mathrm{L}(\mathrm{i}+1) * \operatorname{tau}$;

$\mathrm{r}(\mathrm{k})=\mathrm{d}(\mathrm{i}+1) *(1-\mathrm{tau})$;

$\mathrm{d}(\mathrm{i})=\mathrm{d}(\mathrm{i}+1)-\mathrm{r}(\mathrm{k})$;

$\mathrm{gtl}=\mathrm{gtl}+\mathrm{L}(\mathrm{i})$;

$\mathrm{gt} 2=\mathrm{gt} 2+\mathrm{r}(\mathrm{k})$

$\mathrm{k}=\mathrm{k}-1$;

end

element $=\mathrm{n}$;

for $\mathrm{j}=1: \mathrm{n}$

$\operatorname{disp}(')$;

fprintf(' Length of \%d th element is \% inch

In',j,L(element));

gt $3=(\mathrm{gt} 3+\mathrm{r}(\mathrm{j}))$;

element=element -1 ;

fprintf(' distance of \%d element from 1 st element is \%f inch $\backslash n ', \mathrm{j},(\mathrm{gt} 3 / 2.54))$;

distnc=element +1 ;

if $(j<n)$

fprintf(' Spacing between \%d \& \%d element is \% $\mathrm{cm}$

In',j,j+1,r(distnc)) ;

end

end

fprintf(' Gross total length req. for all elements is \% inch ln',gtl+Lnn)

fprintf(' Gross total space req. for all elements is \% cm\n',gt2)

\section{RESULT}

Table I shows the log periodic dipole antenna design calculated values for Fmin $160 \mathrm{MHz}$, Fmax $1900 \mathrm{MHz}$, scale factor $\tau=0.876$, spacing factor $\sigma=0.161$ and the half apex angle $=\alpha 10.84$ using MATLAB program. The scale factor should be such that its value is less than one. The apex angle should not be too small or too large, since it affects the bandwidth of the antenna. As the frequency increases the spacing factor decreases.

TABLE I ANTENNA PARAMETERS

\begin{tabular}{|l|l|l|}
\hline \multirow{2}{*}{$\begin{array}{l}\text { Sr. } \\
\text { No. }\end{array}$} & \multicolumn{2}{|l|}{ Parameters obtained by program } \\
\cline { 2 - 3 } & Parameters & Values \\
\hline 1 & Fmin & $160 \mathrm{MHz}$ \\
\hline 2 & Fmax & $1900 \mathrm{MHz}$ \\
\hline 3 & dmax & $0.40 \mathrm{in}$ \\
\hline 4 & Tau & 0.876 \\
\hline 5 & Sigma & 0.161 \\
\hline 6 & Alpha & 10.90 \\
\hline 7 & Bar & $1.72 \mathrm{MHz}$ \\
\hline 8 & B & $11.88 \mathrm{MHz}$ \\
\hline 9 & Bs & $20.5 \mathrm{MHz}$ \\
\hline 10 & Lmax & $1.78 \mathrm{~m}$ \\
\hline 11 & L & $7.655 \mathrm{feet}$ \\
\hline 12 & Vapex & $8.02 \mathrm{feet}$ \\
\hline 13 & N & 24 \\
\hline 14 & Stub length & $10.53 \mathrm{in}$ \\
\hline 15 & Za & $272.95 \mathrm{ohm}$ \\
\hline 16 & Zrel & $5.45 \mathrm{ohm}$ \\
\hline 17 & Z0 & 60 ohm \\
\hline 18 & Centre to centre & $1.14 \mathrm{~cm}$ \\
\hline
\end{tabular}


Table II shows the obtained values from the MATLAB relative spacing between the element, stub length etc are to program. It includes the values of 24 elements at top, be calculated in designing. To calculate these antennas bottom side lengths, diameter of the each element in parameter manually is complicated and time consuming. inches and spacing in $\mathrm{cm}$.

\section{TABLE II ANTENNA DESIGN}

\begin{tabular}{|c|c|c|c|c|}
\hline \multirow[b]{2}{*}{$\begin{array}{c}\text { No. } \\
\text { of } \\
\text { Elem } \\
\text { ent }\end{array}$} & \multicolumn{4}{|c|}{$\begin{array}{l}\text { Antenna Design Parameters obtained by } \\
\text { Program }\end{array}$} \\
\hline & $\begin{array}{l}\text { Element } \\
\text { length } \\
\text { (L) } \\
\text { Top side } \\
\text { (in) }\end{array}$ & $\begin{array}{l}\text { Element } \\
\text { length (L) } \\
\text { Bottom } \\
\text { side (in) }\end{array}$ & $\begin{array}{l}\text { Distance } \\
\text { between } \\
R_{n} \text { and } \\
R_{n+1} \\
(\mathrm{~cm})\end{array}$ & $\begin{array}{l}\text { Diamet } \\
\text { er of } \\
\text { element } \\
\text { (d) } \\
\text { (in) }\end{array}$ \\
\hline 01 & 36.90 & 36.90 & 30.35 & 0.40 \\
\hline 02 & 32.32 & 32.32 & 26.58 & 0.40 \\
\hline 03 & 28.32 & 28.32 & 23.39 & 0.40 \\
\hline 04 & 24.80 & 24.80 & 20.40 & 0.40 \\
\hline 05 & 21.73 & 21.73 & 17.87 & 0.40 \\
\hline 06 & 19.03 & 19.03 & 15.65 & 0.40 \\
\hline 07 & 16.67 & 16.67 & 13.71 & 0.40 \\
\hline 08 & 14.60 & 14.60 & 12.01 & 0.40 \\
\hline 09 & 12.79 & 12.79 & 10.52 & 0.40 \\
\hline 10 & 11.21 & 11.21 & 09.21 & 0.40 \\
\hline 11 & 09.82 & 09.82 & 08.08 & 0.40 \\
\hline 12 & 08.60 & 08.60 & 07.07 & 0.40 \\
\hline 13 & 07.53 & 07.53 & 06.20 & 0.40 \\
\hline 14 & 06.60 & 06.60 & 05.43 & 0.40 \\
\hline 15 & 05.78 & 05.78 & 04.76 & 0.40 \\
\hline 16 & 05.06 & 05.06 & 04.17 & 0.40 \\
\hline 17 & 04.43 & 04.43 & 03.65 & 0.40 \\
\hline 18 & 03.88 & 03.88 & 03.20 & 0.40 \\
\hline 19 & 03.40 & 03.40 & 02.80 & 0.40 \\
\hline 20 & 02.98 & 02.98 & 02.42 & 0.40 \\
\hline 21 & 02.61 & 02.61 & 02.15 & 0.40 \\
\hline 22 & 02.28 & 02.28 & 01.88 & 0.40 \\
\hline 23 & 02.00 & 02.00 & 01.65 & 0.40 \\
\hline 24 & 01.76 & 01.76 & - & 0.40 \\
\hline
\end{tabular}
For developing the code, flow-chart is drawn to calculate all these parameters of LPDA. The MATLAB general program was developed to calculate the antenna parameter and structural dimensions for any range of frequencies.

The MATLAB based program provides calculation in the fraction of points which helps to design more accurate structure of LPDA antenna. The MATLAB tools and builtin math functions enable us to explore multiple approaches and reach a solution than traditional programming languages. Using developed MATLAB program, antenna parameters and structure of LPDA for any frequency range can be easily obtained.

\section{ACKNOWLEDGEMENT}

This research is supported by the Principal Dr. Dilip Dhondge and Head, Department of Electronic Science, Dr. M. B. Matsagar of KTHM College, Nashik, Maharashtra, India.

\section{REFERENCES}

[1] D. E. Isbell, "Log-Periodic Dipole Arrays", IEEE Transaction, on Antennas Propagation vol. 8 Issue 3, pp. 260-267, may 1960

[2] R. L. Carrel, "The design of log periodic dipole antenna", IRE International Conversion Rec., pp.61-75, 1961.

[3] J. Mruk, M. Uhm, and D. Filipovic, "Dual-wideband log-periodic antennas", in Proc. IEEE AP-S Int. Symposium, Jul. 2008. Pp. 1-4.

[4] Constantine A. Balanis, "Antenna Theory - Analysis and Design", 3rd ed., a John Wiley \& Sons, Inc. Publication.

[5] Z. S. Hamidi, Z. Z. Abidin, Z. A. Ibrahim, N. N. M. Shariff, "Modification and Performance of Log Periodic Dipole Antenna", International Journal of Engineering Reseaech and Development, Volume 3, Issue 3, Aug2012, PP. 36-39.

[6] Y.T. Lo, S. W. Lee, Antenna Handbook: Theory, Applications, and Design, Springer Science \& Business Media, 2013.

[7] http://www.mathworks.com. MathWorks INC. U.S.

[8] http://in.mathworks.com/help/matlab/

The LPDA is constructed by using two rod alumina type with 24 elements mentioned in table II. Its photograph is shown in fig. 2.

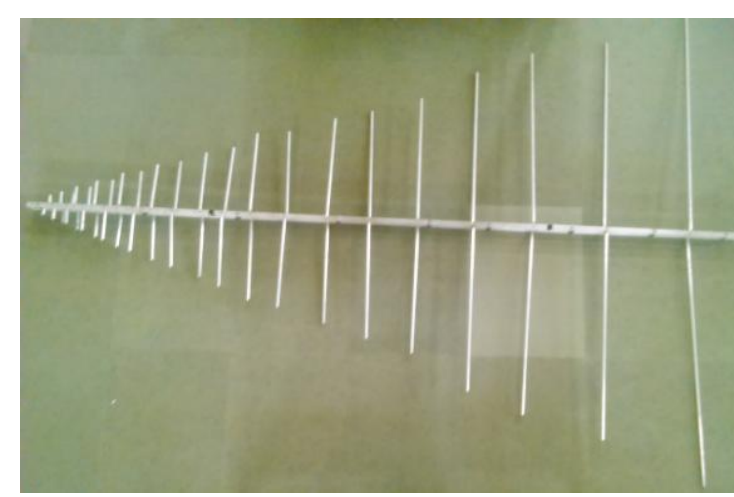

Fig.2. Photograph of designed LPDA

\section{VI.CONCLUSION}

Using mathematical relations of tau $(\tau)$, sigma $(\sigma)$ and half apex angle $(\alpha)$, various parameter of LPDA antenna such as bandwidth, length of structure, number of elements, characteristic impedance, radiation resistance,

\section{BIOGRAPHIES}

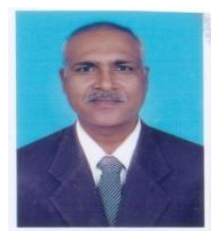

Vijay Kale (M.Sc., M. Phil., Ph.D., PGDIM, ADCSSA) is working as Assistant Professor (Department of Electronic science, KTHM College, Nashik, Maharashtra, India). He has been in the teaching profession (UG and PG) since last 27 years. He has been presented research paper in international conferences (USA, Bangkok). He published research papers in national and international journals. He received R. Chandrasekhar award from Indian Physics Association (IPA), Savitribai Phule Pune University. He has written five books. He is working as research guide to M. Phil. and M.Sc. (Electronic Science) students. He is presently working on e-CALLISTO, DAS, ARM microcontroller based sensor application, Wireless sensor application.

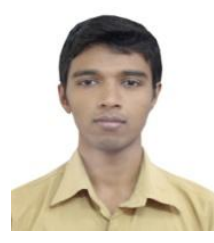

Dnyandev Patil is working as M. Phil. student (Department of Electronic science, KTHM College, Nashik). His research activity is in antenna designing and Sensor based embedded system. He is presently working on e-CALLISTO. 